\title{
Pediatric drug data in Canadian drug monographs: a descriptive analysis
}

\author{
Preeya Raja MSc PharmD, Mark Duffett PhD, Maryann Mazer-Amirshahi PharmD MD PhD, \\ Ashaka Patel BHSc, Andrea Gilpin PhD MBA, Catherine Litalien MD, Anthony K. Chan MBBS, \\ John van den Anker MD PhD, Thierry Lacaze-Masmonteil MD PhD, Samira Samiee-Zafarghandy MD
}

\section{Abstract}

Background: Optimal drug therapy in children relies on the availability of pediatric-specific information. We aimed to describe the current status of pediatric pharmacotherapy data in monographs of new drugs approved by Health Canada.

Methods: In this descriptive analysis, we reviewed the quality and quantity of monographs of new drugs approved by Health Canada between Jan. 1, 2007, and Dec. 31, 2016. We excluded drugs withdrawn from the Canadian market and drugs with primary indications irrelevant to pediatrics. We determined the percentage of included drug monographs that listed pediatric-specific information.

Results: During this study period, Health Canada approved 281 drugs, 270 of which met our inclusion criteria. Pediatric-specific information and indication were present in $127(47.1 \%)$ and $75(27.8 \%)$ of the drug monographs, respectively. Of all pediatric age groups, neonates had the lowest number of indications listed in the product monographs (7, 2.6\%). Only 9 (60\%) oral drugs indicated for children 6 years of age or younger were available in child-friendly, age-appropriate dosage forms.

Interpretation: Most of the new drugs approved by Health Canada do not contain pediatric or neonatal indications in their product monographs, and therefore, are used "off-label." Regulatory mechanisms are required to promote both neonatal and pediatric drug development and submission of available pediatric data by manufacturers to Health Canada.

ptimizing pharmacotherapy in children has been the goal of many American and European legislative initiatives. These initiatives have been introduced to mandate or incentivize pharmaceutical companies to conduct pediatric drug studies and provide equally rigorous therapeutic information for children as for adults. ${ }^{1-3}$

In the United States, the Best Pharmaceuticals for Children Act (BPCA; 2002) and the Pediatric Research Equity Act (PREA; 2003) are some of the acts that encourage pediatric drug development. The Food and Drug Administration Safety and Innovation Act (2012) made the BPCA and PREA into law, including amendments such as a requirement for submission of pediatric study plans by pharmaceutical companies. More recently, in 2017, the Food and Drug Administration Reauthorization Act was signed into law to facilitate the development of drugs and devices for pediatric populations. ${ }^{4}$ In the European Union, the Pediatric Regulation came into force in 2007, and aimed to stimulate the development of pediatric medicines., These regulatory initiatives have resulted in pediatric drug trials, with subsequent labelling changes providing additional pediatric data. ${ }^{7}$
In Canada, the only legislative initiative to include children in drug development, the Pediatric Extension, was implemented in 2006. ${ }^{8}$ This regulation applies only to innovative drugs, and grants a 6-month extension to the 8 -year period of market exclusivity to manufacturers upon the provision of pediatric pharmacotherapy evidence within the first 5 years of drug approval. ${ }^{8}$ This increasing gap in regard to pediatric pharmacotherapy legislative frameworks developed in Canada, as compared with jurisdictions like the US and Europe, ${ }^{9,10}$ can potentially impede the availability of evidence-

Competing interests: Anthony Chan has a patent issued for antithrombin-heparin covalent complex. No other competing interests were declared.

This article has been peer reviewed.

Correspondence to: Samira Samiee-Zafarghandy, samiees@mcmaster.ca

CMAJ Open 2020. DOI:10.9778/cmajo.20200010 
based drug therapy for Canadian children. ${ }^{7,11}$ Our aim was to characterize the current availability of pediatric-specific data in Canadian monographs of new drugs approved between 2007 and 2016.

\section{Methods}

\section{Setting and design}

This study was a descriptive analysis of publicly available pediatric-specific information in recently approved Canadian drug monographs.

\section{Data sources}

We identified new active substances (NASs) approved by Health Canada between Jan. 1, 2007, and Dec. 31, 2016, using the Annual Drug Submission Performance reports (accessed from Health Canada upon e-mail request). New active substances represent new chemicals or biological substances that have not been approved previously for sale as a drug in Canada. We excluded NASs that were withdrawn from the Canadian market or were irrelevant to pediatric pharmacotherapy (Appendix 1, available at www.cmajopen. $\mathrm{ca} /$ content/8/3/E522/suppl/DC1). Oncology drugs were deemed irrelevant to pediatric pharmacotherapy if their molecular targets were listed in the US Food and Drug Administration (FDA)'s Pediatric Molecular Target List as irrelevant to pediatrics ${ }^{12}$ (Appendix 2, available at www. cmajopen.ca/content/8/3/E522/supp1/DC1). For nononcology drugs, we excluded those that were indicated for adult-specific conditions (Appendix 1).

\section{Data collection}

The most recent versions of drug monographs were obtained from Health Canada's Drug Product Database. ${ }^{13}$ We reviewed each monograph for the availability and quality of pediatric-specific clinical and dosing information, specifically the presence of pediatric indications, dosing, safety, pharmacokinetic data and the availability of child-friendly oral dosage forms (Appendix 3, available at www.cmajopen.ca/content /8/3/E522/suppl/DC1). Pediatric, term and preterm neonatal indications were defined as an approved use in populations 17 years of age or younger, 27 or fewer days of life, and less than 37 weeks of gestation, respectively, in accordance with Health Canada's pediatric population age cut-off. ${ }^{14,15} \mathrm{We}$ defined pediatric information as the presence of any data pertaining to the use of a particular medication in children, and we defined safety information as pediatric-specific warnings, contraindications or adverse effects.

Drug formulations included those specifically designed for pediatric use, such as oral liquids, granules, mini-tablets, dispersible tablets or chewable tablets, as these formulations better enable age-appropriate oral drug delivery. ${ }^{16}$ This definition excludes tablets and capsules that pediatric populations may be unable to swallow.

We classified drugs into 19 therapeutic categories according to their primary indication and mechanism of action. ${ }^{17}$ For monographs that included pediatric data, we recorded the study type, design and population from the data source (e.g., published study).

Two authors (A.P. and P.R.) and 2 independent reviewers extracted the data and entered the information into a REDCap database. To ensure accuracy of the collected data, the first 10 drugs reviewed by each abstractor $(n=40)$ and a random sample $(10 \%)$ of all remaining drugs $(n=23)$ were reviewed, and modified if necessary, by an independent reviewer and the most senior reviewer (P.R.). Discrepancies were discussed among 2 authors (S.S.-Z. and P.R.) until a consensus was obtained.

\section{Statistical analysis}

We used counts with percentages and means with standard deviations to report the characteristics of the included NASs. We calculated the percentage of NASs with pediatric indications and the associated confidence intervals. We used the Cochran-Armitage test for trend to assess the differences in the percentage of NASs with a pediatric indication by age group and by year of approval. We reported data for all NASs and for the subgroups of nonbiologic and biologic drugs. We used R Version 3.6.0 (R Foundation for Statistical Computing) to perform the analysis and $p<0.05$ as the criterion for statistical significance.

\section{Ethics approval}

Ethics approval was not required for this study as all data collected are publicly available and not patient-specific.

\section{Results}

Health Canada approved a total of 281 new drugs between 2007 and 2016. We included 270 of these drugs, excluding 2 with the same medicinal ingredient (nitisinone), 4 that were withdrawn from the Canadian market (ezogabine, sitaxsentan, daclizumab and idebenone) and 5 that were irrelevant to pediatric pharmacotherapy (degarelix, a gonadotropin-releasing hormone receptor antagonist; abiraterone and enzalutamide, androgen biosynthesis inhibitors; rivastigmine for Alzheimer disease; and bazedoxifene-conjugated estrogens for vasomotor symptoms associated with menopause). The years with the lowest and highest number of approvals were 2008 and 2013, with 16 and 39 drug approvals, respectively. Duplicated data collection for the random sample completed by an independent reviewer and author (P.R.) had a discrepancy rate of $4 \%$.

Of all monographs, 265 (98.0\%) listed an adult indication. The 5 monographs with only pediatric indications were 3 biological products (10-valent adsorbed pneumococcal conjugate vaccine, meningococcal group B vaccines [Neisseria meningitidis group B NZ98/254 strain, recombinant Neisseria meningitidis group B NHBA fusion protein, recombinant Neisseria meningitidis group B NadA protein or recombinant Neisseria meningitidis group B fHBP fusion protein], an oral vaccine (human rotavirus RIX4414 strain) and 1 drug for the treatment of attention-deficit/hyperactivity disorder (guanfacine).

Table 1 lists the NASs categorized in 19 therapeutic classes. The classes with the greatest number of drugs were 
oncology $(57,21.2 \%)$, infectious disease $(39,14.3 \%)$ and hematology (26, 9.5\%). The routes of administration were oral (138, 51.2\%), intravenous (107, 39.5\%) and topical (23, $8.6 \%)$. At the time of data abstraction, 248 (91.9\%) NAS monographs had been revised since the original approval of the drug, with most $(223,82.6 \%)$ being revised between 2016 and 2018.

Pediatric information, including pediatric-specific indications, dosing or safety information, was available in 127 (47.1\%) drug monographs. Pediatric indications were listed in $75(27.8 \%)$ monographs. The 4 therapeutic classes with the highest number of drugs with pediatric indications were infectious disease (18 of 39, 46.2\%), hematology (11 of 26, $42.3 \%$ ), allergy or immunology (10 of $17,58.7 \%$ ) and endocrine or metabolic (10 of $24,41.5 \%)$. None of the drugs in anesthesia or analgesia, dermatology, urology or toxicology had pediatric indications (Table 1).

Across all therapeutic classes, pediatric dosing information, when present, was most often available for the adolescent age group (12-17 yr). No pediatric indications were included in the monographs of drugs approved for critical conditions such as pulmonary arterial hypertension, diabetes, hepatitis $\mathrm{C}$ and invasive systemic infections (Table 2). All 127 monographs with pediatric indications provided pediatric dosing recommendations; however, most of the pediatric indications and dosing information pertained to the adolescent age group (12-17 yr; 68 of $75,90.5 \%)$ and decreased by age, with only 6 of $75(8.0 \%)$ and 1 of 75 $(1.4 \%)$ monographs providing indication and dosing recommendations for term and preterm infants, respectively (Figure 1). Of 31 drugs formulated for oral use in pediatric populations, 15 drugs were indicated for children 6 years of age or younger. We found that only 9 of these 15 drugs $(60.0 \%)$ were available in a child-friendly oral dosage form.

Pediatric-specific safety information was included in 98 $(36.3 \%)$ drug monographs. Specifically, pediatric-specific adverse effects, warnings and contraindications were present in $74(27.3 \%), 63(23.4 \%)$ and $14(5.0 \%)$ monographs, respectively. The source of pediatric information was from studies in exclusively pediatric populations $(71,55.9 \%)$, mixed pediatric and adult populations (35, 27.6\%), animals (13, 10.3\%) and studies on different drugs in the same class $(7,5.6 \%)$. In

Table 1: Pediatric-specific indication and child-friendly, age-appropriate oral dosage forms for new drugs, by therapeutic drug class

\begin{tabular}{|c|c|c|c|c|c|}
\hline \multirow[b]{2}{*}{ Therapeutic class } & \multicolumn{5}{|c|}{ No. $(\%)$ of NASs } \\
\hline & $\begin{array}{l}\text { Approved } \\
n=270\end{array}$ & $\begin{array}{c}\text { Pediatric } \\
\text { indication } \\
(\text { all })^{*}\end{array}$ & $\begin{array}{c}\text { Nonbiologics } \\
\text { approved, } \\
n=198\end{array}$ & $\begin{array}{l}\text { Pediatric indication } \\
\text { (nonbiologic) } \dagger\end{array}$ & $\begin{array}{c}\text { Child-friendly oral } \\
\text { dosage form } \ddagger\end{array}$ \\
\hline Oncology & $57(21.1)$ & $4 / 57(7.0)$ & 39 (19.6) & $1 / 39(2.4)$ & 0 \\
\hline Infectious disease & $39(14.4)$ & $18 / 39(46.1)$ & $33(16.6)$ & 12/33 (36.2) & $3 / 21(14.2)$ \\
\hline Hematology & $26(9.6)$ & $11 / 26(42.3)$ & $12(6.0)$ & $2 / 12(16.5)$ & $1 / 10(10.0)$ \\
\hline Endocrine or metabolic & $24(8.8)$ & $10 / 24(41.6)$ & $16(8.0)$ & 4/16 (25.0) & $3 / 13(23.0)$ \\
\hline Cardiology & $20(7.4)$ & $3 / 20(15.0)$ & $17(8.4)$ & 2/17 (11.6) & $1 / 15(6.6)$ \\
\hline Allergy or immunology & $17(6.2)$ & $10 / 17(58.8)$ & $4(2.0)$ & $1 / 4(25.0)$ & $1 / 3(33.3)$ \\
\hline Neurology & $15(5.6)$ & 4/15 (26.6) & $14(7.0)$ & 4/14 (28.9) & $3 / 10(30.0)$ \\
\hline Pulmonology & $15(5.6)$ & $5 / 15(33.3)$ & $13(6.4)$ & $5 / 13(38.3)$ & $1 / 6(16.6)$ \\
\hline Gastrointestinal & $12(4.4)$ & $3 / 12(25.0)$ & $11(5.6)$ & 2/11 (18.2) & $1 / 8(12.5)$ \\
\hline Ophthalmology & $10(3.7)$ & $2 / 10(20.0)$ & $8(4.0)$ & $2 / 8(25.0)$ & 0 \\
\hline Psychiatry & $10(3.7)$ & $2 / 10(20.0)$ & $10(5.0)$ & $2 / 10(20.0)$ & 0 \\
\hline Rheumatology & $8(2.9)$ & $1 / 8(12.5)$ & $4(2.0)$ & 0 & 0 \\
\hline Obstetrics or gynecology & $5(1.8)$ & 1/3 (33.3) & $3(1.5)$ & $1 / 3(33.4)$ & 0 \\
\hline Anesthesia or analgesia & $3(1.1)$ & 0 & $3(1.5)$ & 0 & 0 \\
\hline Dermatology & $3(1.1)$ & 0 & $3(1.5)$ & 0 & 0 \\
\hline Diagnostic imaging & $3(1.1)$ & $1 / 3(33.4)$ & $3(1.5)$ & $1 / 3(33.4)$ & 0 \\
\hline Urology & $3(1.1)$ & 0 & $3(1.5)$ & 0 & 0 \\
\hline Nephrology & $2(0.7)$ & $1 / 2(50.0)$ & $2(1.0)$ & $1 / 2(50.0)$ & $1 / 2(50.0)$ \\
\hline Toxicology & 0 & 0 & 0 & 0 & 0 \\
\hline Total & 270 & 75 & 198 & 40 & 15 \\
\hline $\begin{array}{l}\text { Note: NAS = new active substar } \\
{ }^{*} \text { Percentage expressed of all N } \\
\text { †Percentage expressed of all nc } \\
\text { fPercentage expressed of all dr }\end{array}$ & $\begin{array}{l}\text { tic class. } \\
\text { in therapeu } \\
\text { e available ir }\end{array}$ & ge forms. & & & \\
\hline
\end{tabular}


Table 2: Availability of pediatric information in drug monographs by therapeutic class and indications

\begin{tabular}{|c|c|c|c|c|c|c|c|c|c|}
\hline \multirow[b]{2}{*}{$\begin{array}{l}\text { Therapeutic } \\
\text { class }\end{array}$} & \multicolumn{7}{|c|}{ Monographs presenting pediatric indications, by age group } & \multirow[b]{2}{*}{ Total } & \multirow[b]{2}{*}{$\begin{array}{l}\text { Indications of drugs approved for adults with } \\
\text { no pediatric information* }\end{array}$} \\
\hline & $\begin{array}{c}12-17 \\
y r\end{array}$ & $\begin{array}{c}6-11 \\
\mathrm{yr}\end{array}$ & $\begin{array}{c}2-5 \\
y r\end{array}$ & $\begin{array}{l}28 \mathrm{~d}- \\
1 \mathrm{yr}\end{array}$ & Neonates & Preterm & $\begin{array}{l}\text { Age not } \\
\text { specified }\end{array}$ & & \\
\hline $\begin{array}{l}\text { Allergy or } \\
\text { immunology }\end{array}$ & 8 & 7 & 7 & 4 & 0 & 0 & 1 & 10 & $\begin{array}{l}\text { Crohn disease, plaque psoriasis, seasonal } \\
\text { allergic rhinitis or conjunctivitis, systemic lupus } \\
\text { erythematosus, ulcerative colitis }\end{array}$ \\
\hline $\begin{array}{l}\text { Anesthesia or } \\
\text { analgesia }\end{array}$ & 0 & 0 & 0 & 0 & 0 & 0 & 0 & 0 & $\begin{array}{l}\text { Intensive care unit sedation, severe pain, } \\
\text { topical analgesia }\end{array}$ \\
\hline Cardiology & 2 & 2 & 0 & 0 & 0 & 0 & 0 & 2 & $\begin{array}{l}\text { Arrhythmia, atrial fibrillation, dyslipidemia, } \\
\text { familial hypercholesteremia, heart failure, } \\
\text { hypertension, perioperative hypertension, } \\
\text { pulmonary arterial hypertension }\end{array}$ \\
\hline Dermatology & 0 & 0 & 0 & 0 & 0 & 0 & 0 & 0 & $\begin{array}{l}\text { Actinic keratosis, basal cell carcinoma, } \\
\text { eczema, rosacea }\end{array}$ \\
\hline $\begin{array}{l}\text { Diagnostic } \\
\text { imaging }\end{array}$ & 1 & 1 & 1 & 1 & 1 & 0 & 0 & 1 & Hepatic or cardiac vascular imaging \\
\hline $\begin{array}{l}\text { Endocrine or } \\
\text { metabolic }\end{array}$ & 10 & 10 & 10 & 8 & 2 & 0 & 0 & 10 & Cushing syndrome, diabetes, lipodystrophy \\
\hline Gastrointestinal & 3 & 2 & 2 & 1 & 1 & 0 & 0 & 3 & $\begin{array}{l}\text { Chronic idiopathic constipation, cirrhosis, } \\
\text { irritable bowel syndrome, opioid-induced } \\
\text { constipation, nausea or vomiting }\end{array}$ \\
\hline Hematology & 8 & 7 & 7 & 3 & 1 & 0 & 3 & 11 & $\begin{array}{l}\text { Anemia, embolism treatment and } \\
\text { prevention, hemostasis, stroke prevention, } \\
\text { thrombocytopenic purpura, polycythemia } \\
\text { vera }\end{array}$ \\
\hline $\begin{array}{l}\text { Infectious } \\
\text { disease }\end{array}$ & 17 & 13 & 10 & 7 & 1 & 1 & 0 & 18 & $\begin{array}{l}\text { Clostridium difficile infection, hepatitis C, } \\
\text { human immunodeficiency virus, intra- } \\
\text { abdominal infections, invasive systemic fungal } \\
\text { infections, methicillin-resistant Staphylococcus } \\
\text { aureus infections, onychomycosis, pneumonia, } \\
\text { skin infections }\end{array}$ \\
\hline Nephrology & 1 & 1 & 0 & 0 & 0 & 0 & 0 & 1 & Hyponatremia \\
\hline Neurology & 3 & 2 & 2 & 0 & 0 & 0 & 1 & 4 & $\begin{array}{l}\text { Parkinson disease, dementia, partial-onset } \\
\text { seizures, restless leg syndrome, relapsing } \\
\text { remitting multiple sclerosis, reversal of } \\
\text { neuromuscular blockade }\end{array}$ \\
\hline $\begin{array}{l}\text { Obstetrics or } \\
\text { gynecology }\end{array}$ & 1 & 0 & 0 & 0 & 0 & 0 & 0 & 1 & $\begin{array}{l}\text { Uterine fibroids, vasomotor symptoms } \\
\text { associated with menopause }\end{array}$ \\
\hline Oncology & 4 & 4 & 3 & 2 & 0 & 0 & 1 & 4 & $\begin{array}{l}\text { Acute lymphoblastic leukemia, breast cancer, } \\
\text { Castleman disease, chronic lymphocytic } \\
\text { leukemia, chronic myelogenous leukemia, } \\
\text { colorectal cancer, gastric cancer, } \\
\text { hepatocellular carcinoma, leukemia, } \\
\text { lymphoma, melanoma, multiple myeloma, } \\
\text { non-small cell lung carcinoma, ovarian } \\
\text { cancer, renal cell carcinoma, soft tissue } \\
\text { sarcoma, prostate cancer }\end{array}$ \\
\hline Ophthalmology & 2 & 2 & 2 & 1 & 0 & 0 & 0 & 2 & $\begin{array}{l}\text { Actinic keratosis, age-related macular } \\
\text { degeneration, ocular pain, open angle } \\
\text { glaucoma, postoperative inflammation }\end{array}$ \\
\hline Psychiatry & 2 & 0 & 0 & 0 & 0 & 0 & 0 & 2 & $\begin{array}{l}\text { Anxiety, maintenance of alcohol abstinence, } \\
\text { antipsychotics, major depressive disorder }\end{array}$ \\
\hline Pulmonology & 5 & 3 & 2 & 0 & 0 & 0 & 0 & 5 & $\begin{array}{l}\text { Chronic obstructive pulmonary disease, } \\
\text { chronic bronchitis, emphysema, asthma, } \\
\text { idiopathic pulmonary fibrosis }\end{array}$ \\
\hline Rheumatology & 1 & 1 & 1 & 0 & 0 & 0 & 0 & 1 & Gout, psoriatic arthritis, rheumatoid arthritis \\
\hline Urology & 0 & 0 & 0 & 0 & 0 & 0 & 0 & 0 & $\begin{array}{l}\text { Benign prostatic hyperplasia, overactive } \\
\text { bladder }\end{array}$ \\
\hline Total & 68 & 55 & 47 & 27 & 7 & 1 & 6 & 75 & \\
\hline
\end{tabular}




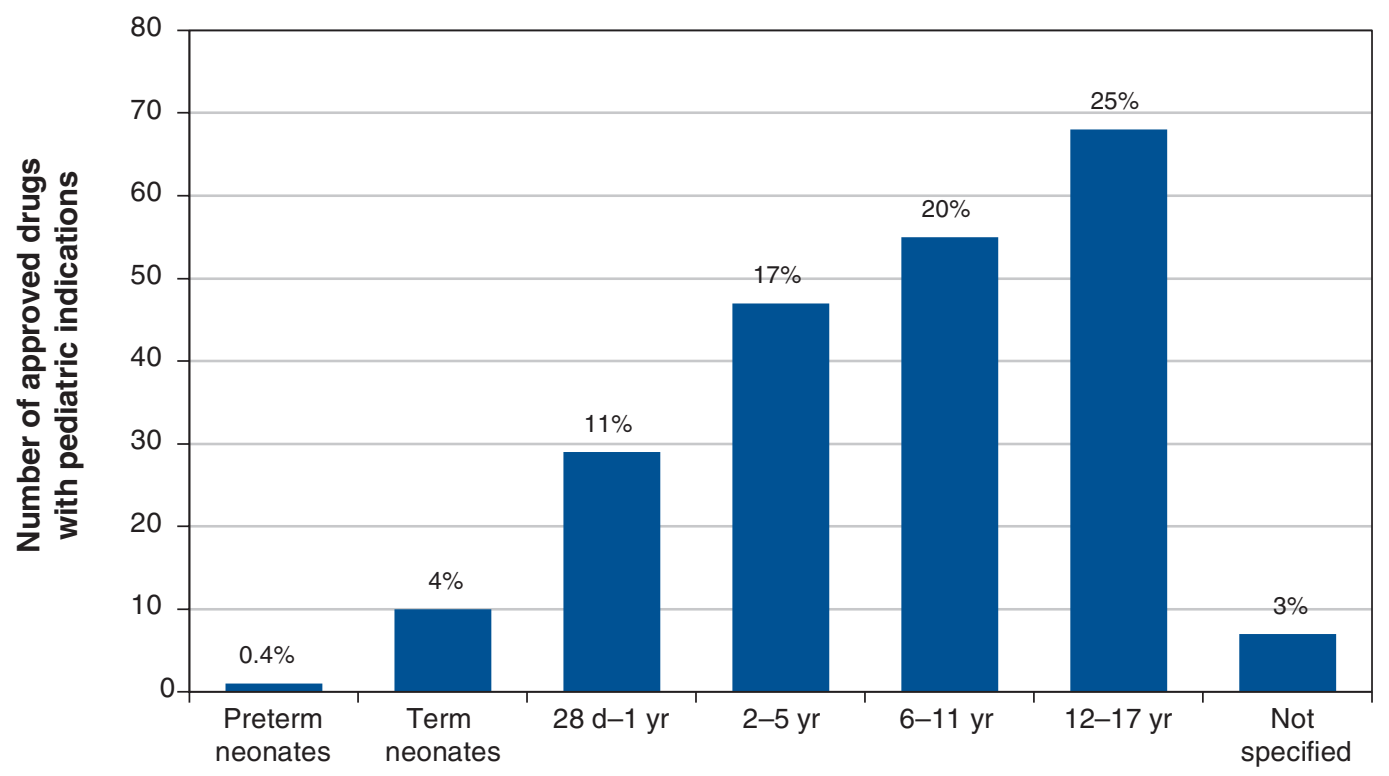

Age group

Figure 1: Age-specific pediatric indications for 270 new drugs approved by Health Canada (2007-2016). Note: The percentage of all drugs with a pediatric indication in each age category are shown. Cochran-Armitage test for trend $p<0.001$.

addition, in one drug monograph, pediatric information was based on studies exclusively in adults.

Of all NASs, 198 (73.4\%) were nonbiologics. In this subgroup of drugs, 83 (42.0\%) and 40 (20.1\%) monographs contained pediatric information and indications, respectively. The safety information and child-friendly oral formulations were similar to the total NASs (32\% and 9\%, respectively). Availability of dosing information for different pediatric age groups also followed the same pattern as the total NASs (Figure 1). Of the 72 biologic products, 35 (48.7\%) included a pediatric indication in their most recent labelling, 9 (25.8\%) of which were vaccines. The nonvaccine biologic products with pediatric indications belonged to hematology $(n=9)$, infectious disease $(n=1)$, endocrine or metabolic disease $(n=6)$, allergy or immunology $(n=5)$, oncology $(n=2)$, cardiology $(n=1)$, gastrointestinal $(n=1)$ and rheumatology $(n=1)$ classes.

The annual percentage of drugs with pediatric indications listed in the most recent drug monographs did not show any clear pattern of improvement over the 10 -year period of the study (Figure 2).

\section{Interpretation}

Our findings show that less than one-third of drugs approved by Health Canada over a recent 10 -year period contain a pediatric indication in their most recent monographs and less than half include any pediatric information. Furthermore, when a drug monograph was found to include a pediatric indication along with dosing information, it was most often for the adolescent age group (12-17 yr), leaving out children, infants and neonates. Our study included new drugs approved after the implementation of Health Canada's Pediatric Extension legislation, with most included drugs having been given between 3 and 5 years to include pediatric information in their monographs.

We did not observe any clear pattern of improvement over the study period regarding the presence of pediatric indications in the newly approved drugs, reflecting either the lack of pediatric efficacy and safety data or failure of manufacturers to submit existing pediatric information to Health Canada. Both possibilities suggest that the market exclusivity incentive alone may be insufficient in Canada's small pediatric market and underline the importance of a Canadian regulatory framework that promotes availability of pediatric data in monographs.

Aside from a lack of indications, $40 \%$ of the drugs with oral dosage forms that were indicated for children 6 years of age or younger had unmet needs for pediatric formulations. The lack of available pediatric formulations leads to manipulation of adult pharmaceutical forms for use in children, which can cause medication errors as well as safety and toxicity problems. ${ }^{18}$ Child-friendly, age-appropriate drug formulation is an essential part of pediatric pharmacotherapy, and the new pediatric regulatory environment in the US and Europe has resulted in a global collaboration to strengthen its development. ${ }^{19}$

We observed that despite clear advancement in therapeutic options for critical conditions like psychotic disorders, 


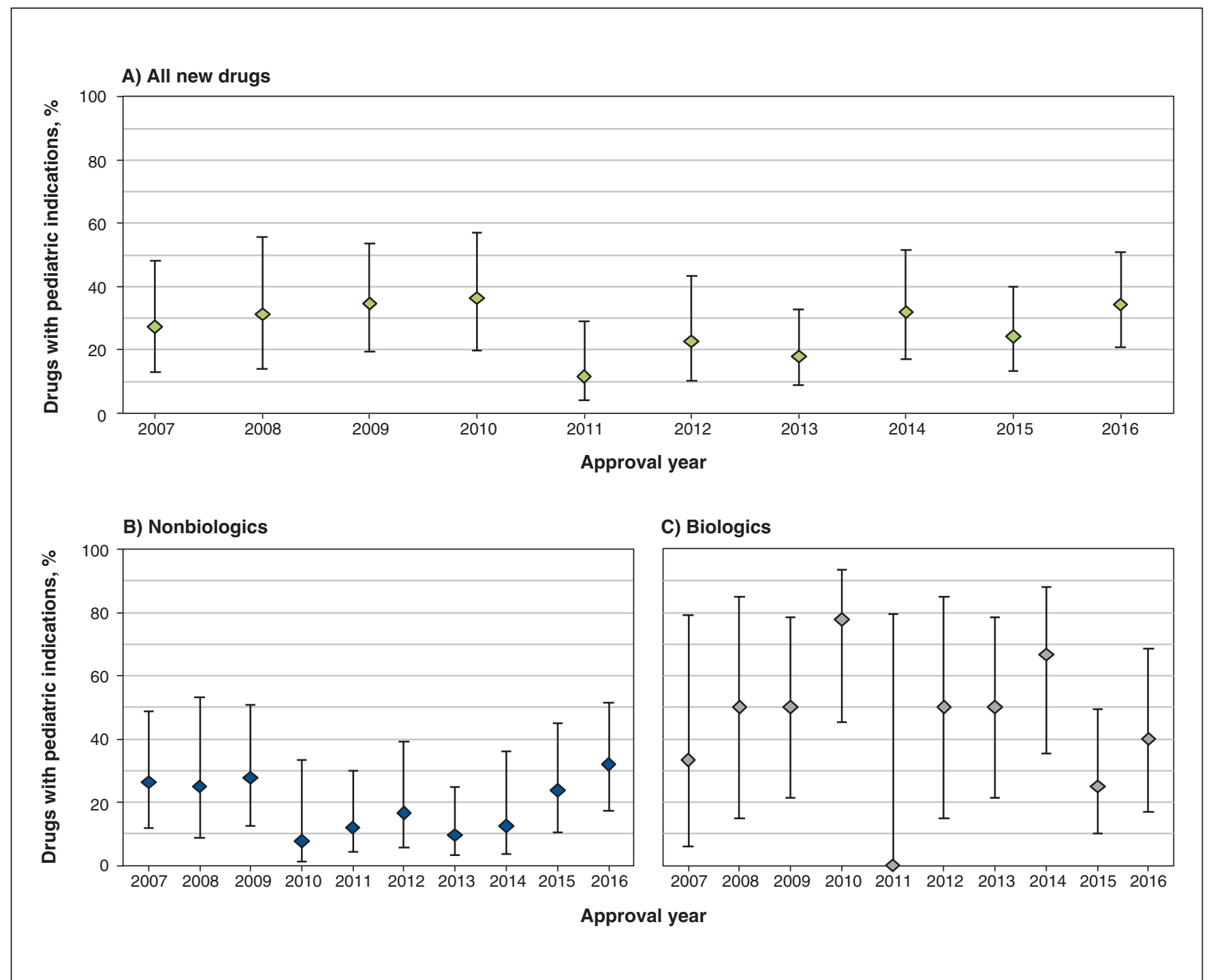

Figure 2: Percentage of new drugs approved by Health Canada with a pediatric indication (2007-2016) for (A) all new drugs $(p$ value for trend $=0.94)$, $(B)$ nonbiologics ( $p$ value for trend $=0.94$ ) and $(C)$ biologics $(p$ value for trend $=0.25)$. Note: Error bars show the $95 \%$ confidence interval. $p$ values from Cochran-Armitage tests for linear trend.

invasive systemic fungal infections, hepatitis C, methicillinresistant Staphylococcus aureus infections or pulmonary hypertension for adults, the monographs of only a few of these newly approved therapies contained pediatric indications and none had any neonatal information. This finding is concerning as such health conditions are associated with major morbidity, death and a substantial financial burden on neonatal and pediatric health care..$^{20}$ The lack of information in monographs pertaining to the neonatal population calls for action, as critically ill infants admitted to neonatal intensive care units are exposed to a large number of medications, most of which do not have safety, efficacy and dosing information for this age group. ${ }^{21,22}$

For almost all drugs with pediatric indications, we found an overlapping adult indication, reinforcing the available evidence that new drug approvals are mainly driven by adult standards, ${ }^{17}$ leaving Canadian children as therapeutic orphans.
We observed that except for 5 drugs, all drugs that were newly approved during the period of study were either approved for conditions that could occur in a pediatric population or had a molecular target (oncology drugs) substantially relevant to the progression of a pediatric cancer. As per the Research to Accelerate Cures and Equity for Children Act in the US, the pediatric applicability of new molecular entities for oncology should be reviewed based on their molecular target rather than the pediatric relevance of their adult indication, as this can accelerate pediatric oncology drug development. ${ }^{23,24}$

Since the first pediatric drug development regulatory initiative was enacted by the US FDA in 1997, more than 1200 pediatric studies have been submitted to the FDA, and 700 drug labels have been revised. ${ }^{2}$ The extent to which these data have been translated to Health Canada's approved drug monographs is unknown. There is evidence for a systematic delay of up to 2 years in submission of new drugs to Health 
Canada compared with regulatory authorities in the US and Europe. ${ }^{11}$ The delay in submission of pediatric trial data by pharmaceutical companies means these data are not readily accessible in Canada. Furthermore, given the observed paucity of pediatric indications in our studied drugs, it is unclear to what degree the available pediatric information ultimately reaches the Canadian drug monographs. This delay in the new drug submission is largely a result of Canada's small market share. ${ }^{11}$ Authorizing Health Canada to proactively mandate the submission of pediatric data from manufacturers, combined with incentives, may rectify this situation.

The past 20 years have shown the clear advancement of pediatric drug development worldwide. ${ }^{2}$ Regulatory authorities in the US and Europe and the pharmaceutical industry collaborate closely to ensure appropriate assessment of drug safety and efficacy in children across all age groups. ${ }^{5}$ The American and European governmental initiatives, which mandate and monitor pediatric medicine research, can provide a useful framework for Canadian legislators. ${ }^{7}$ As the drug approval process in Canada is primarily industry driven, regulatory mandates for pediatric drug development should come into force to increase the data contained in regulatory submissions when use in children is expected. ${ }^{19}$

\section{Limitations}

A limitation of this study is the potential for errors in data extraction and coding. We analyzed only the pediatric data included in the most recent drug monograph, not at the time of initial approval. However, this provided us with the most current information available for Canadian children. Lastly, our study reviewed the availability of pediatric information specifically in drug monographs and did not review existing Canadian or global pediatric trial data. A comparison of trial data with that available in Canadian drug monographs would offer a valuable perspective.

\section{Conclusion}

Newly approved drugs in Canada lack important pediatric information, perpetuating "off-label" use in this vulnerable population. To provide Canadian children with safe and effective drug therapy, regulatory mechanisms are needed to ensure submission of pediatric data by manufacturers when use in children is anticipated. Such regulations will help promote pediatric drug studies and enhance the inclusion of existing pediatric information in Canadian drug monographs, all of which will contribute to optimal pediatric pharmacotherapy in Canadian children.

\section{References}

1. Turner MA, Catapano M, Hirschfeld S, et al.; Global Research in Paediatrics. Paediatric drug developments: the impact of evolving regulations. Adv Drug Deliv Rev 2014;73:2-13.

2. Bucci-Rechtweg C. Enhancing the pediatric drug development framework to deliver better pediatric therapies tomorrow. Clin Ther 2017;39:1920-32.

3. Brown RE Jr. Evaluation of drugs for use in infants and children: Where are we now, and where must we go? Anesth Analg 2019;129:1170-4.

4. Taiwan Travel Act. One hundred fifteenth congress of the United States of America at the second session. H.R. 535. Available: www.congress.gov/115/ bills/hr535/BILLS-115hr535enr.pdf (accessed 2020 Jan. 7).
5. Penkov D, Tomasi P, Eichler I, et al. Pediatric medicine development: an overview and comparison of regulatory processes in the European Union and United States. Ther Innov Regul Sci 2017;51:360-71.

6. Tomasi PA, Egger GF, Pallidis C, et al. Enabling development of paediatric medicines in Europe: 10 years of the EU Paediatric Regulation. Paediatr Drugs 2017;19:505-13

7. Rieder MJ; Canadian Paediatric Society, Drug Therapy and Hazardous Substances Committee. Drug research and treatment for children in Canada: a challenge. Paediatr Child Health 2011;16:560-1.

8. 2.8, Pediatric extension. In: Data protection under C.08.004.1 of the Food and Drug Regulations [guidance document]. Ottawa: Health Canada; modified 2011 July 10. Available: www.canada.ca/en/health-canada/services/drugs-health-products/ drug-products/applications-submissions/guidance-documents/guidance -document-data-protection-under-08-004-1-food-drug-regulations.html\#a28 (accessed 2018 Sept. 3).

9. Denburg AE, Ungar WJ, Greenberg M. Public drug policy for children in Canada. CMA7 2017;189:E990-4.

10. European Medicines Agency and its Paediatric Committee. 10-year report to the European Commission: general report on the experience acquired as a result of the application of the Paediatric Regulation. London (UK): European Medicines Agency; 2016. Available: https://ec.europa.eu/health/sites/health/files/files/ paediatrics/2016_pc_report_2017/ema_10_year_report_for_consultation.pdf (accessed 2020 Jan. 7).

11. Shajarizadeh A, Hollis A. Delays in the submission of new drugs in Canada. CMA7 2015;187:E47-51.

12. Relevant molecular targets in pediatric cancers: applicability to pediatric therapeutic investigations required under FDARA 2017 [briefing document]. Silver Spring (MD): US Food and Drug Administration; 2018. Available: www.fda.gov/ media/112230/download (accessed 2019 July 10).

13. Drug product database online query. Ottawa: Health Canada; modified 2019 Mar. 19. Available: https://health-products.canada.ca/dpd-bdpp/ (accessed 2019 Dec. 1).

14. Notice: therapeutic products with pediatric labelling. Ottawa: Health Canada; modified 2015 Feb. 12. Available: www.canada.ca/en/health-canada/corporate/ about-health-canada/reports-publications/health-products-food-branch/notice -therapeutic-products-paediatric-labelling.html (accessed 2020 May 17).

15. Notice - Adoption of ICH guidance: clinical investigation of medicinal products in the pediatric population E11. Ottawa: Health Canada; modified 2003 Dec. 17. Available: www.canada.ca/en/health-canada/services/drugs-health-products/ drug-products/applications-submissions/guidance-documents/international -conference-harmonisation/efficacy/industry-clinical-investigation-medicinal -products-pediatric-population-topic.html (accessed 2020 Jan. 17).

16. Lopez FL, Ernest TB, Tuleu C, et al. Formulation approaches to pediatric oral drug delivery: benefits and limitations of current platforms. Expert Opin Drug Deliv 2015;12:1727-40.

17. Samiee-Zafarghandy S, Mazer-Amirshahi M, van den Anker JN. Trends in pediatric clinical pharmacology data in US pharmaceutical labelling. Arch Dis Child 2014;99:862-5.

18. Ivanovska V, Rademaker CMA, van Dijk L, et al. Pediatric drug formulations: a review of challenges and progress. Pediatrics 2014;134:361-72.

19. Thomsen MD. Global pediatric drug development. Curr Ther Res Clin Exp 2019; 90:135-42.

20. Calley JL, Warris A. Recognition and diagnosis of invasive fungal infections in neonates. 7 Infect 2017;74(Suppl 1):S108-13.

21. Ziesenitz VC, Fox E, Zocchi M, et al. Prescription drug shortages: impact on neonatal intensive care. Neonatology 2019;115:108-15.

22. Kumar P, Walker JK, Hurt KM, et al. Medication use in the neonatal intensive care unit: current patterns and off-label use of parenteral medications. $\mathcal{F}$ Pediatr 2008; 152:412-5.

23. The US Pediatric Equity Act and Race for Children ACT. ACCELERATE Platform. Available: www.accelerate-platform.org/whyplatform/the-platform/ us-pediatric-equity-act-race-children-act/ (accessed 2019 July 10).

24. Pediatric oncology. Silver Spring (MD): US Food and Drug Administration; 2018. Available: www.fda.gov/about-fda/oncology-center-excellence/pediatric -oncology (accessed 2020 Apr. 1).

Affiliations: Department of Pharmacy (Raja), Hamilton Health Sciences; Departments of Pediatrics (Duffett), and Health Research Methods, Evidence, and Impact (Duffett), McMaster University, Hamilton, Ont.; Department of Emergency Medicine (Mazer-Amirshahi), MedStar Washington Hospital Center, Washington, DC; Faculty of Health Sciences (Patel), McMaster University, Hamilton, Ont.; The Rosalind \& Morris Goodman Family Pediatric Formulations Centre of the SainteJustine University Hospital Center (Gilpin, Litalien), Montréal, Que.; Division of Pediatric Hematology/Oncology (Chan), McMaster Children's Hospital, McMaster University, Hamilton, Ont.; Division of Clinical Pharmacology (van den Anker), Department of Pediatrics, Children's National Health System, Washington, DC; Division of Paediatric Pharmacology and Pharmacometrics (van den Anker), University of Basel Children's Hospital, Basel, Switzerland; Division of Neonatology 
(Lacaze-Masmonteil), Department of Pediatrics, University of Calgary, Alberta Children's Hospital, Calgary, Alta.; Division of Neonatology (Samiee-Zafarghandy), Department of Pediatrics, McMaster Children's Hospital, McMaster University, Hamilton, Ont.

Contributors: Preeya Raja, Mark Duffett and Samira Samiee-Zafarghandy contributed substantially to conception and design. Ashaka Patel and Preeya Raja contributed substantially to acquisition of data. Maryann Mazer-Amirshahi, Preeya Raja, Samira Samiee-Zafarghandy and Thierry Lacaze-Masmonteil contributed substantially to analysis and interpretation of data. Preeya Raja and Samira Samiee-Zafarghandy drafted the article. Preeya Raja, Mark Duffett, Maryann Mazer-Amirshahi, Ashaka Patel, Andrea Gilpin, Catherine Litalien, Anthony Chan, John van den Anker, Thierry Lacaze-Masmonteil and Samira Samiee-Zafarghandy revised the article critically for important intellectual content; gave final approval of the version to be published; and agreed to act as guarantors of the work.

Funding: The authors received no financial support for the research, authorship or publication of this article.

Data sharing: All data presented are available through the appendices.

Acknowledgements: The authors thank Victor Lam, Natalie Tchakerian and Grace Xu for acting as independent reviewers and Ayfer Karaokcu for his assistance with obtaining Health Canada's Annual Drug Submission Reports.

Supplemental information: For reviewer comments and the original submission of this manuscript, please see www.cmajopen.ca/content/8/3/ E522/suppl/DC1. 